\title{
INTERCOLONIAL AGGRESSION IN THE SUBTERRANEAN TERMITE HETEROTERMES AUREUS (ISOPTERA: RHINOTERMITIDAE)*
}

\author{
By Bradley F. Binder \\ Department of Entomology, University of Arizona \\ Tucson, Arizona 85721
}

\section{INTRODUCTION}

Foraging parties of the subterranean termite, Heterotermes aureus, are present throughout the year in the southwestern United States, but peak foraging activity coincides with the summer "monsoon" season when the weather is warm with ample precipitation (Haverty et al., 1974). Average foraging territory for a colony of $H$. aureus is estimated to be approximately 12.5 square meters and each colony apparently maintains a discrete boundary with other conspecific colonies (Haverty et al., 1975). How these termites achieve colony isolation is unknown, although aggressive interactions have been observed between groups of conspecifics (Nutting, unpublished observations). Intraspecific territoriality and aggressive behavior have been described in other termites (Clément, 1978; Darlington, 1982; Greaves, 1962; Howick and Creffield, 1980; Levings and Adams, 1984; Nel, 1968; Thorne, 1982) and in several other social insects (Hölldobler and Lumdsen, 1980; Levings and Traniello, 1981). The events preceding an encounter between individuals, the recognition and discrimination factors, and the consequences of aggression are not well understood in $H$. aureus. This study was done to examine the aggressive behavior between $H$. aureus colonies from different field locations and describe intercolony interactions of both paired individuals and simulated foraging groups.

\section{Materials AND Methods}

\section{Termites}

Groups of $\boldsymbol{H}$. aureus were collected at various locations surrounding Tucson, Arizona, during the spring and fall of 1986. Fallen

*Revised manuscript received by the editor October 4, 1987 
branches and dead trunks of Cercidium floridum (blue palo verde) or C. microphyllum (little-leaf palo verde) were used as a source of termites even though $H$. aureus will utilize a variety of desert plants as hosts (Haverty and Nutting, 1975). The branches were brought back to the laboratory at the University of Arizona and the termites extracted from each branch. Each termite group from a single tree was maintained separately in a plastic shoe box lined with moist paper towels.

\section{Arenas}

Rectangular arenas were assembled for pairs of termites from two thin plastic strips and two machine nuts. The components were arranged so the plastic strips were adjacent to the machine nuts and the unit placed on paper to give the termites a "grip." This construction made manipulation of arena size easy and deterred termite escape. Glass arenas were used for simulated foraging studies (Fig. 1). The arena dimensions were $17 \times 21 \times 1 \mathrm{~cm}$ and could accommodate approximately 1000 termites.

Soldier and worker interactions: arena size

Each soldier was placed in an arena and observed until its behavior stabilized. A soldier or worker from the same colony was introduced and the pair observed for 3 minutes. The added soldier or worker was removed and a soldier or worker from a different colony was placed in the arena with the same soldier for 3 minutes. Observations for soldier/soldier interactions were at a single arena size $\left(1.5 \mathrm{~cm}^{2}\right)$ while soldier/worker observations were made at 4 arena sizes $\left(1.5,3.0,4.5\right.$, and $\left.6.0 \mathrm{~cm}^{2}\right)$. Two replicates of 10 soldiers, each with 8 pairings of different workers, were completed for a total of 160 observations. During the 3-minute period the number of snaps of the mandibles was recorded, the time to a fatal snap, the number of encounters, and any behavior that was consistent throughout the course of the experiment.

Soldier vs. worker interactions: immobilization of soldiers or workers

Termite aggression was investigated by immobilizing workers or soldiers between the head and the thorax with a small card with a $\mathrm{V}$-shaped notch cut in the edge. The immobilization procedure in no way injured the animal, because normal behavior resumed when the card was lifted. In one experiment only the worker head was exposed to a freely moving soldier. In another, only the worker 


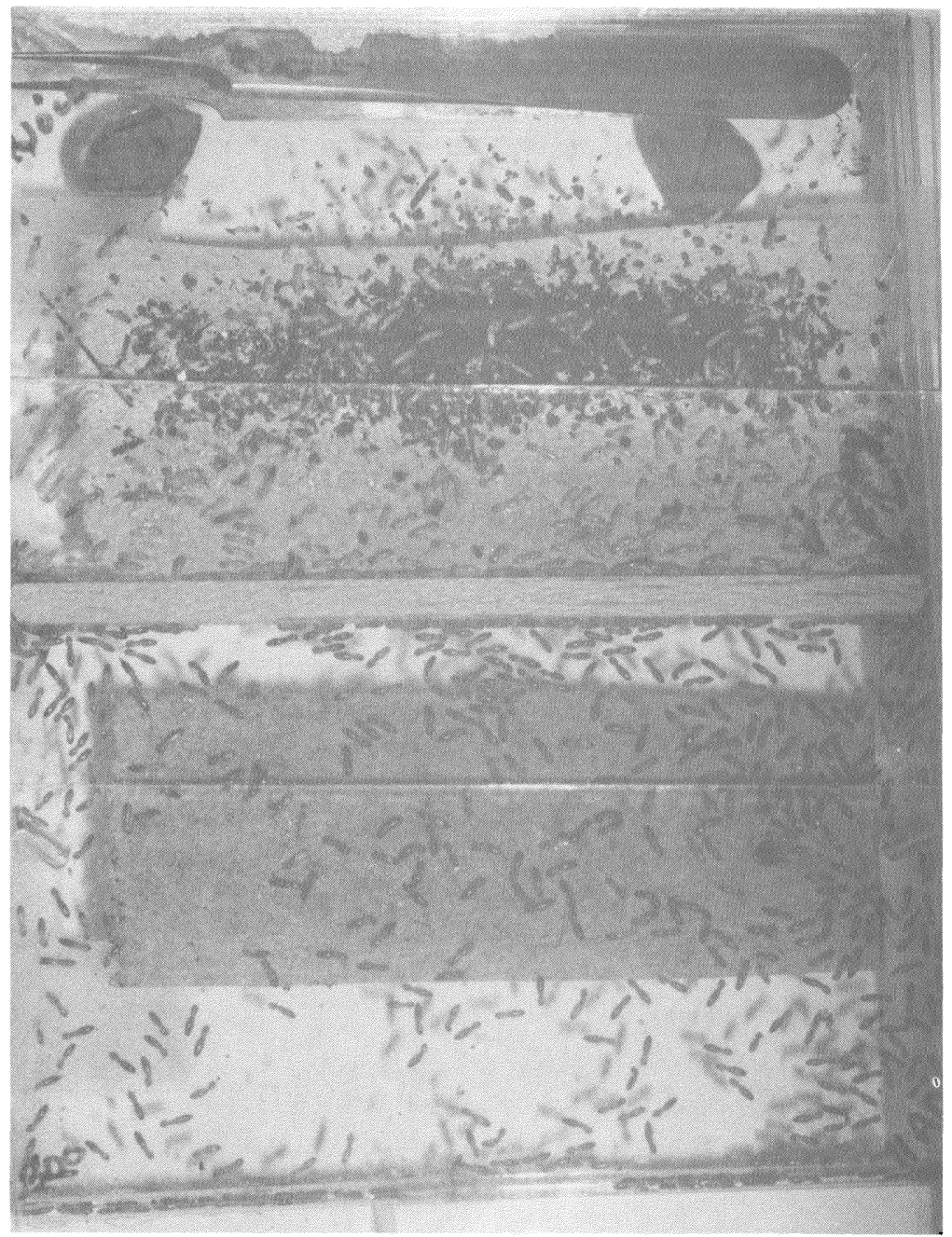

Figure 1. Arena for simulated foraging tests of conspecific, intercolonial aggression of Heterotermes awreus.

abdomen was exposed to a freely moving soldier. Similar observations were made of worker behavior when soldiers were immobilized with only the abdomen or only the head exposed. Ten pairings in each of the four categories were made. 
Simulated foraging experiments

Termites are generally found in foraging groups when observed in the field. Field conditions were simulated in the laboratory with a glass arena containing a balsawood barrier to separate termites from different colonies (experimental) or from the same colony (control) (Fig. 1). One group of termites was dyed with Sudan Red 7B by the method of Lai et al. (1983) before each experiment. Large groups (approximately 500) of mixed soldiers and workers were placed on each side of the arena. The termites required approximately 1 hour to start foraging behavior and nearly 8 hours to penetrate the barrier. Termite behaviors were documented and examined using high magnification video recording equipment.

\section{ReSULTS}

Soldier vs. soldier interactions

When two soldiers from different colonies were paired in an arena, each would walk until there was contact. These encounters resulted in a brief to extended period of antennation, followed by the retreat of one or both, opening and repeated snapping of the mandibles. A fatal snap resulted when the mandibles penetrated the head, thorax, or abdomen. Snaps which severed only an antenna or leg were not fatal. Soldiers that had delivered a fatal snap made several additional contacts, an occasional snap, and moved away as if no longer considering the "enemy" a threat. There were further contacts by the victorious soldier but no snaps. The mechanism by which the soldier made this decision is unknown.

Soldier vs. worker interactions: arena size

Intracolonial termite pairs of soldier and worker had a mean number of encounters/minute ( \pm standard error) of $3.0 \pm 0.2$ at 1.5 $\mathrm{cm}^{2}, 2.5 \pm 0.2$ at $3.0 \mathrm{~cm}^{2}, 2.2 \pm 0.2$ at $4.5 \mathrm{~cm}^{2}$, and $1.6 \pm 0.2$ at 6.0 $\mathrm{cm}^{2}$ (Figure 2a). Intercolonial encounters between soldier and worker also decreased with an increase in arena size. The mean number of encounters/minute ( \pm standard error) for intercolony pairings was $2.0 \pm 0.2,2.2 \pm 0.2,1.7 \pm 0.2$, and $1.4 \pm 0.1$ at arena sizes of $1.5,3.0,4.5$, and $6.0 \mathrm{~cm}^{2}$ respectively (Figure $2 \mathrm{a}$ ). While there was no aggression during intracolony pairings, most intercolony pairings resulted in soldier displays of aggression, including attack posture (open mandibles against the substrate), numerous snaps of the mandibles, and rapid retreats. At every arena size more 

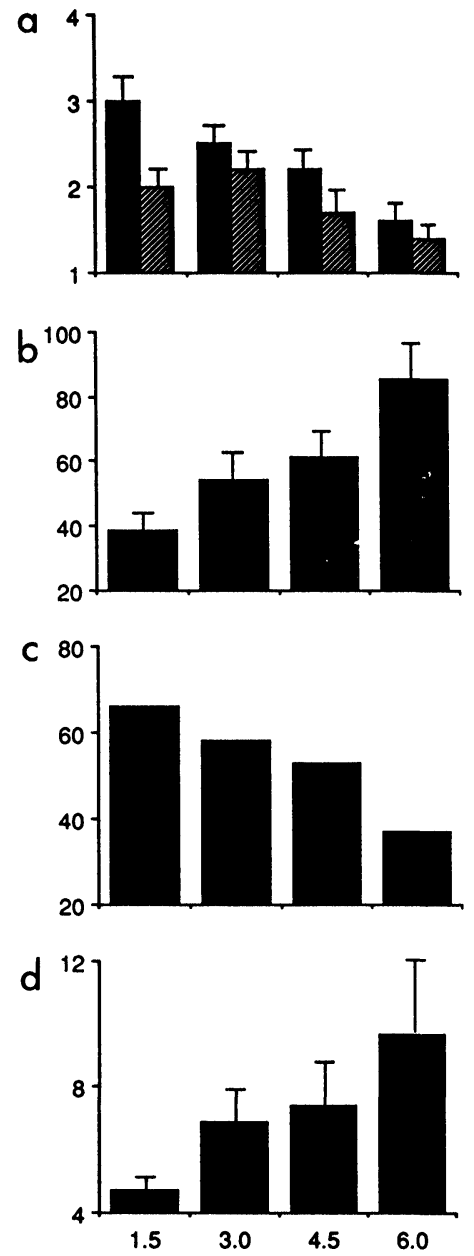

Figure 2. Heterotermes aureus encounters in an arena. The horizontal axis represents increase in arena size $\left(\mathrm{cm}^{2}\right)$. Vertical lines on each column represent standard error. a) Intracolonial (hatched) vs intercolonial (solid) mean number of encounters per minute. b) Mean time soldiers require to inflict fatal snaps on alien workers (seconds). c) Percentage of soldier encounters following a fatal snap against a worker. d) Mean number of snaps a soldier requires to inflict a fatal snap on a worker. 
than $50 \%$ of the workers were fatally wounded. Only the soldier made additional contacts following a fatal snap while both the soldier and the worker participated in encounters if there was no fatal snap. Again, soldiers refrained from further snaps during contacts after a fatal snap. Soldiers delivered a fatal snap in a mean time ( \pm standard error) of $37 \pm 7$ seconds in a $1.5 \mathrm{~cm}^{2}$ arena, $51 \pm 10$ seconds in a $3.0 \mathrm{~cm}^{2}$ arena, $62 \pm 8$ seconds in a $4.5 \mathrm{~cm}^{2}$ arena, and 80 \pm 13 seconds in a $6.0 \mathrm{~cm}^{2}$ arena (Fig. 2b). The percentage of soldier encounters following a fatal snap decreased as the arena size increased and was $66 \%$ at $1.5 \mathrm{~cm}^{2}, 58 \%$ at $3.0 \mathrm{~cm}^{2}, 53 \%$ at $4.5 \mathrm{~cm}^{2}$, and $37 \%$ at $6.0 \mathrm{~cm}^{2}$ (Fig. 2c). The number of encounters following a fatal snap by a soldier was higher at smaller arena sizes since the encounter rate was higher and more than $80 \%$ of the fatal snaps were delivered by the third encounter. The soldier also required fewer snaps to deliver a fatal snap as arena size diminished (Figure 2d).

Even though the response of a soldier to an alien worker was more rapid as arena size decreased, not all workers were killed. Some avoided a fatal encounter with a soldier; escape was most frequent at the largest arena size (Table 1). In fact, $25 \%$ of the workers behaved aggressively and attacked a soldier. Aggressive workers were usually slashed by the sharp and powerful soldier mandibles but a few workers were able to evade the soldier defenses. During these encounters the soldier became the victim, having one or both antennae removed just above the scape. The behavior of workers when confronted with an aggressive soldier was grouped in two categories: 1) the worker responded actively (ran away or became aggressive), or 2) the worker remained stationary (no motion). Each category had a nearly equal probability but more workers survived if their behavior was active (Table 2).

Soldier vs. worker interactions: immobilization of soldiers or workers

Worker behavior toward a soldier and soldier behavior toward a worker were distinguished when one of the individuals was immobilized while the other moved freely. Soldier snaps to the worker abdomen were less frequent and less violent than snaps to the worker head (Table 3). Workers approached the abdomen of an immobilized soldier, made brief touches with the antennae and retreated. The worker attacked vigorously until the cuticle was 
Table 1. The evasion of soldier aggression by workers during all intercolony pairings of workers and soldiers.

\begin{tabular}{|c|c|c|}
\hline \multirow[b]{2}{*}{ Arena size $\left(\mathrm{cm}^{2}\right)$} & \multicolumn{2}{|c|}{ Worker evasion } \\
\hline & no. ${ }^{\mathrm{a}}$ & $\%^{\mathrm{a}}$ \\
\hline 1.5 & 4 & 20 \\
\hline 3.0 & 3 & 15 \\
\hline 4.5 & 4 & 20 \\
\hline \multirow[t]{2}{*}{6.0} & 9 & 45 \\
\hline & \multicolumn{2}{|c|}{ Total } \\
\hline
\end{tabular}

aEach value based on 20 pairs of termites

Table 2. Comparison of worker behavior and survival during all intercolony pairings of soldiers and workers.

\begin{tabular}{|c|c|c|}
\hline & \multicolumn{2}{|c|}{ Worker response } \\
\hline & no. & $\%$ \\
\hline & \multicolumn{2}{|c|}{ active } \\
\hline Initial behavior & $44 / 80$ & 55 \\
\hline Within group survival & $17 / 44$ & 39 \\
\hline \multirow[t]{2}{*}{ Total survival } & $17 / 80$ & 21 \\
\hline & \multicolumn{2}{|c|}{ passive } \\
\hline Initial behavior & $36 / 80$ & 45 \\
\hline Within group survival & $3 / 36$ & 8 \\
\hline Total survival & $3 / 80$ & 4 \\
\hline
\end{tabular}

Table 3. The aggressive response of soldiers to immobilized workers and the aggressive response of workers to immobilized soldiers. ${ }^{a}$

\begin{tabular}{lccccc}
\hline & \multicolumn{2}{c}{ Immobilized workers } & & \multicolumn{2}{c}{ Immobilized soldiers } \\
\cline { 2 - 3 } \cline { 5 - 6 } & $\begin{array}{c}\text { Abdomen } \\
\text { exposed }\end{array}$ & $\begin{array}{c}\text { Head } \\
\text { exposed }\end{array}$ & & $\begin{array}{c}\text { Abdomen } \\
\text { exposed }\end{array}$ & $\begin{array}{c}\text { Head } \\
\text { exposed }\end{array}$ \\
\hline $\begin{array}{l}\text { Aggressive response } \\
\text { on first encounter }\end{array}$ & $3 \mathrm{~b}$ & 5 & & 3 & 7 \\
$\begin{array}{l}\text { Aggressive response } \\
\text { after } 3 \text { encounters }\end{array}$ & 3 & 5 & & 10 & 9 \\
\hline
\end{tabular}

aAggressive responses followed encounters of individuals of different colonies and resulted in a snap of the mandibles by the soldier or a worker attack

bEach column represents the actual number of individuals responding of 10 pairs of termites 
penetrated if there was a second encounter. When the worker contacted the head of an immobilized soldier there was repeated movement of the worker's mandibles but no penetration of the heavily armored soldier head capsule. Eventually the soldier's antennae were snipped off just above the scape or the labrum was damaged.

\section{Simulated foraging experiments}

Four experiments were completed. Experimental and control trials were made on October 1, 1986. The experimental group contained 300 workers and 15 soldiers (undyed) on one side of the balsawood barrier and 500 workers and 15 soldiers (dyed) from another colony on the other. A similar control group contained 500 workers and 15 soldiers from the same colony on each side with one of the groups dyed. The soldier/worker ratio in these experiments was similar to soldier/worker ratio of $\boldsymbol{H}$. aureus foraging groups in the field (Haverty, 1977). After the normalization period, workers of both experimental groups began removing bits of the wood partition. Upon antennal contact with alien workers, some workers abandoned their activity, retreated backwards out of the hole, and began Vertical Oscillatory Movement (V.O.M.) (Howse, 1964). Many termites became agitated, moved rapidly, and soldiers clustered around the breach in the barrier (Figure 3). The soldiers in the hole impeded tunneling, but a few workers excavated more wood. Some soldiers arched the abdomen, perhaps releasing a sternal gland substance. After 30 minutes, 2 dyed workers penetrated to the side of the undyed colony and within 15 minutes more than 100 dyed termites (both workers and soldiers) had migrated to the undyed termite side while only 55 undyed termites moved to the dyed termite area. After 24 hours only 5 dyed individuals remained alive. Meanwhile, control groups had penetrated at about the same time as the experimentals but no agonistic behavior was observed. After 24 hours, members of the dyed and undyed control groups were completely mixed. These results demonstrated that intercolony contact of large foraging groups led to aggression which was not terminated at colony boundaries. The soldier's contribution to the successful invasion was not clear, so two more tests were made on November 1, 1986. One test contained 500 workers from different colonies on either side, with no soldiers. All the termites were dead after 24 hours. The coincident trial contained 500 workers on either side but one side contained 8 soldiers (dyed) while the other side contained 25 soldiers (undyed). When the hole was large enough, 


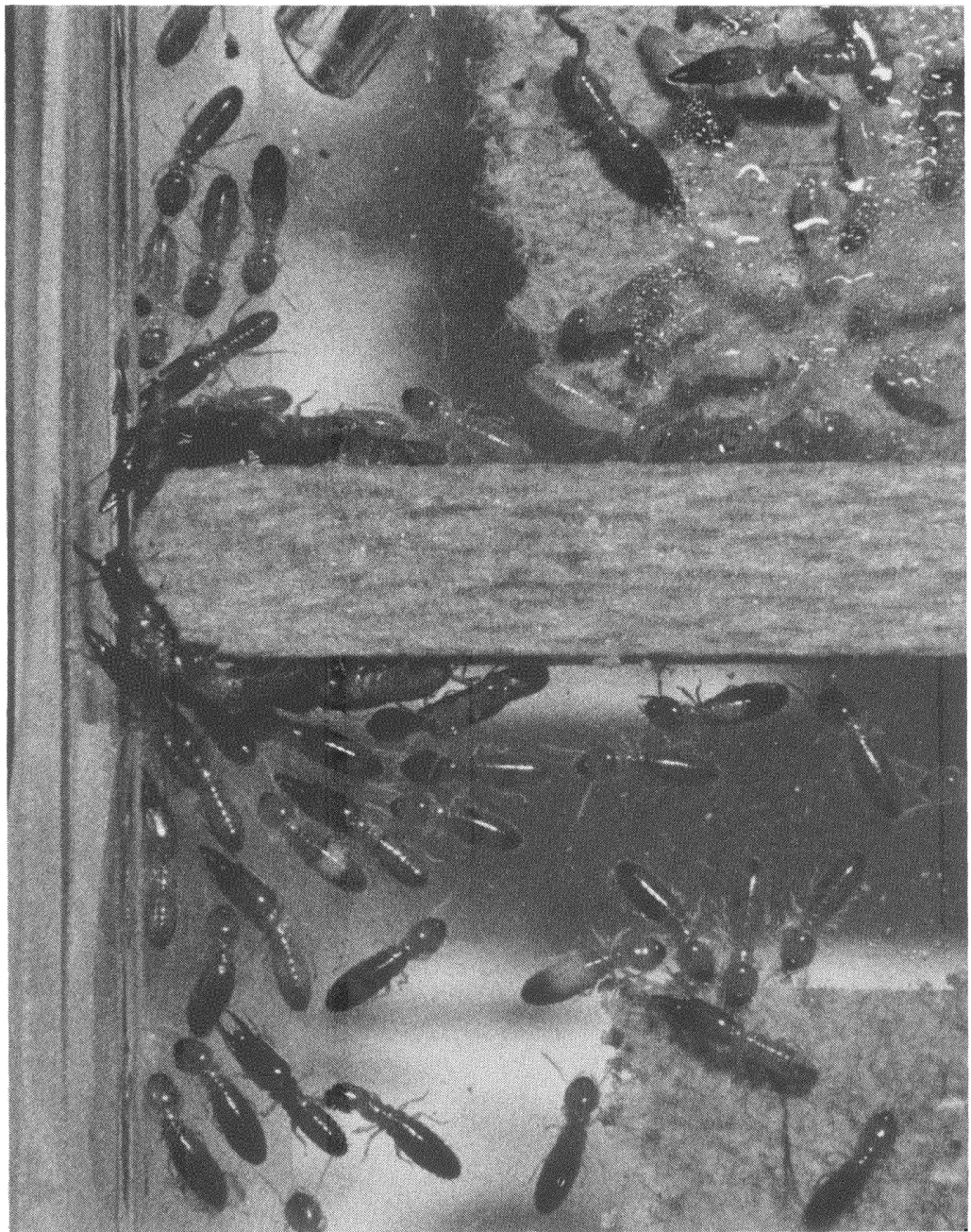

Figure 3. Soldier aggregation at orifices between groups during simulated foraging of Heterotermes aureus.

several undyed workers immediately penetrated to the side of the dyed termites. The invasion resulted in vigorous attacks by the dyed termites but after 24 hours all of the dyed termites were dead while there were still numerous undyed termites searching the arena. 


\section{Discussion}

Both workers and soldiers of $H$. aureus were able to distinguish individuals of their own colony from those of an alien colony and recognition always followed some type of body contact. Intercolony pairings of soldiers or soldiers and workers resulted in aggression with the death of one individual while in similar intracolony pairings there was no aggression or mortality. Recognition after body contact was especially evident when several intra- and intercolony switches were made sequentially. The contacts were probably the result of random movement and not a response to a pheromone, because the number of encounters/minute decreased for both intraand intercolonial pairings with an increase in arena size. Moreover, workers were not alarmed until there was contact of the antennae during simulated foraging. Body contact is also part of alarm communication of Zootermopsis angusticollis and Z. nevadensis (Stuart, 1970).

Repeated contacts in small arenas intensified aggression between individuals of $\boldsymbol{H}$. aureus resulting in more encounters and fewer encounters to a fatal snap. The termites could have been stimulated by contact behavior or increased exposure to cuticular and/or glandular substances. Cuticular hydrocarbons are associated with interspecific and caste recognition cues in the termite, Reticulitermes virginicus (Howard et al., 1982a, 1982b). The role of cuticular hydrocarbons in the conspecific intercolonial interactions of $R$. virginicus is unclear because pooled extracts of termites from widely separated locations ( $>1.6 \mathrm{~km}$ apart) were used. These termites were almost certainly from separate colonies, and some agonistic behavior would be expected which could not be conclusively evaluated by a behavioral assay (Howard et al., 1982a). Nevertheless, cuticular hydrocarbons could be an important factor for communication during $\boldsymbol{H}$. aureus encounters, since workers and soldiers became excited after body contact. Furthermore, there was recognition and alarm after contact of only the antennae during simulated foraging. Soldiers also became excited and moved into the orifice between groups; some of the soldiers arched the abdomen and may have released an abdominal sternal gland substance which helped excite both soldiers and workers. Soldier sternal gland pheromone is important for recruiting soldiers and workers to areas of interspecific confrontation in Nasutitermes costalis (Traniello, 1981). Soldierless foraging 
groups of $\boldsymbol{H}$. aureus penetrated, invaded, and attacked another colony similarly to foraging groups with soldiers, so that the actual contribution of a soldier's cuticular or glandular substance to the increased excitement of the termites is uncertain.

Complex behavior followed paired and multi-termite contacts in H. aureus. After encounters of paired termites from the same colony, the soldier or both the soldier and the worker made a few V.O.M.'s. Most V.O.M.'s, however, occurred during intercolony pairings, so it may be an alarm signal as suggested by Howse (1965). Workers were responsible for the initial intercolonial discrimination in simulated foraging experiments and then transmitted a warning via vibrational signals (V.O.M.'S) to the remainder of the colony. Worker V.O.M.'s are probably important cues to "call" soldiers to the area of contention. The source and the identity of the discrimination cue (i.e. cuticular chemicals or complex behavior) is still unknown.

Soldiers and workers behaved differently when given similar experimental treatments. A worker confronted with an immobilized alien soldier attacked. A soldier confronted with an immobilized alien worker did not immediately respond aggressively. The soldier may not have recognized the worker as "different" or immobilization prevented worker behavior critical for discrimination. Soldiers respond to cuticular and/or secretory substances in paired encounters but were more likely to acknowledge vibrational cues during simulated foraging. $H$. aureus soldiers in normal foraging conditions may be relegated to a defensive/offensive role as observed in other termites (Prestwich, 1984; Stuart, 1969; Thorne, 1982) and may not participate in intercolonial encounters until summoned by the workers giving vibrational signals.

Workers and soldiers have different roles in overall colony aggression. Workers made initial contact with other colony members in simulated foraging experiments. They then triggered a sequence of events which recruited soldiers to the area of confrontation, widened the orifice between colonies, and were first to invade new territory. Workers were also aggressive in the absence of soldiers. The worker's primary role in intercolony contacts, agonistic behavior, and defense has been described in Nasutitermes corniger (Thorne, 1982). The $N$. corniger workers attack soldiers vigorously, biting the legs and abdomen and $H$. aureus workers behave similarly. Soldiers that penetrated to the other colony area in simulated 
foraging experiments, were immediately confronted by a squad of both soldiers and workers. Instead of retreating, the workers attacked the soldier's abdomen, legs, and head. Many workers were killed by the soldier but it was eventually subdued. The worker's behavior helped increase its survival and might be important in securing and protecting territory. How worker behavior is integrated in the foraging dynamics of natural groups of termites is unclear.

The role of the soldier was also important in simulated foraging. The number of soldiers participating in the interactions was critical to the successful invasion of one colony by another. When the number of soldiers was equivalent, there was nearly complete decimation of both simulated foraging groups regardless of the number of workers. When the number of soldiers was disproportionate, the group with the larger number of soldiers successfully invaded. Since soldiers migrate into areas of conflict between groups, the soldier density may be substantially greater in natural foraging groups where intercolonial or interspecific confrontations are frequent. Locations in the colony interior may have few soldiers, so the soldier ratios suggested by Haverty (1977) could be an artifact of the collection procedure. Unfortunately, $H$. aureus colonies are difficult to excavate, so the absolute numbers of different caste members and their distribution is not known. The number of soldiers available for protection is important for colony preservation and may even contribute to territory expansion. Therefore, the number of soldiers in $H$. aureus colonies under natural conditions is probably highest in the aggravated parts of the colony or at intercolonial (interspecific and intraspecific) boundaries.

Actual aggressive interactions between natural colonies of $\boldsymbol{H}$. aureus have never been observed. Large colonies may invade and destroy smaller colonies of $H$. aureus or other termites to secure and control additional resources (i.e. nesting areas, moisture) and food. Foraging populations attack areas providing ample vegetation, although foraging is random once a suitable site is located (Jones et al., 1987). If colony aggression helps stabilize (Haverty et al., 1975) or enlarge territories of $\boldsymbol{H}$. aureus, I would expect large dominant colonies with infrequent small colonies. Large colonies would increase the ecological and/or economic impact of this species in areas with few competitors and predators. The aggressive behavior 
of $\boldsymbol{H}$. aureus could also have an important influence on the intraand interspecific associations of various termite populations in the Southwest.

\section{SumMary}

Aggressive behavior of individuals and groups of Heterotermes aureus was studied in the laboratory. Intracolony pairing of soldiers resulted in no aggression. Intercolony pairing of soldiers always resulted in aggression and the mortality of one soldier. Similarly, intercolony pairing of a soldier and a worker resulted in aggression and a high rate of worker mortality, while intracolony pairing of a soldier and a worker resulted in no aggression.

The number of encounters between paired soldiers and workers decreased with increase in arena size. Soldiers had fewer opportunities for aggression, required more time to inflict a fatal snap of the mandibles, and more snaps to kill a worker with increase in arena size. Consequently, fewer workers had fatal encounters at the largest arena size. Workers also had a greater chance for survival by behaving aggressively or running away and were more likely to attack soldiers after multiple encounters.

Foraging of large groups of termites was simulated in the laboratory to study intra- and intercolony dynamics. Intercolonial groups, each with the same number of soldiers, maintained continuous agonistic engagements, established no common boundaries, and the death of all termites resulted. A foraging group with more soldiers, however, was able to invade another group's territory. Workers were first to recognize foreign colony members and recruit more termites, while soldiers crowded into the orifice to protect existing territory. The impact of conspecific, intercolony aggression in natural termite communities is discussed.

\section{ACKNOWLEDGMENTS}

The author would like to thank Dr. Susan Jones for supplying many undyed termites and the dyed termites used in this study. Drs. William L. Nutting, Floyd G. Werner, David N. Byrne and Timothy G. Myles made critical comments during the preparation of this manuscript. 


\section{REFERENCES}

Clément, J.-L. 1978. L'agression interspécifique et intraspècifique des espéces francaises Reticulitermes (Isoptère). Comptes rendus, l'Academie des Sciences, Paris (series D) 286: 351-354.

Darlington, J. P. E. C. 1982. The underground passages and storage pits used in foraging by a nest of the termite Macrotermes michaelseni in Kajiado, Kenya. Journal of Zoology, London 198: 237-247.

Greaves, T. 1962. Studies of the foraging galleries and the invasion of living trees by Coptotermes acinaciformis and C. brunneus (Isoptera). Australian Journal of Zoology 10: 630-651.

HAVERTY, M. I. 1977. The proportion of soldiers in termite colonies: a list and bibliography (Isoptera). Sociobiology 2: 199-216.

Haverty, M. I. AND NutTing, W. L. 1975. Natural wood preferences of desert termites. Annals, Entomological Society of America 68: 533-536.

Haverty, M. I., LaFage, J. P., Nutting, W. L. 1974. Seasonal activity and environmental control of foraging of the subterranean termite, Heterotermes aureus (Snyder), in a desert grassland. Life Sciences 15: 1091-1101.

Haverty, M. I., Nutting, W. L., And LaFage, J. P. 1975. Density of colonies and spatial distribution of foraging territories of the desert subterranean termite, Heterotermes aureus (Snyder). Environmental Entomology 4: 105-109.

Hölldobler, B. AND LUMSDEN, C. J. 1980. Territorial strategies in ants. Science 210: 732-739.

Howard, R. W., McDaniel, C. A., Nelson, D. R., Blomquist, G. J., Gelbaum, L. T., AND ZALKOW, L. H. 1982a. Cuticular hydrocarbons of Reticulitermes virginicus (Banks) and their role as potential species- and caste-recognition cues. Journal of Chemical Ecology 8: 1227-1239.

Howard, R. W., McDaniel, C. A., And Blomquist, G. J. 1982b. Chemical mimicry as an integrating mechanism for three termitophiles associated with Reticulitermes virginicus (Banks). Psyche 89: 157-167.

Howick, C. D. AND Creffield, J. W. 1980. Intraspecific antagonism in Coptotermes acinaciformis (Froggatt) (Isoptera: Rhinotermitidae). Bulletin of Entomological Research 70: 17-23.

Howse, P. E. 1964. The significance of sound produced by the termite Zootermopsis angusticollis (Hagen). Animal Behaviour 12: 284-300.

Howse, P. E. 1965 . On the significance of certain oscillatory movements of termites. Insectes Sociaux 12: 335-346.

Jones, S. C., Trosset, M. W., and Nutring, W. L. 1987. Biotic and abiotic influences on foraging of Heterotermes aureus (Snyder) (Isoptera: Rhinotermitidae). Environmental Entomology 16: 791-795.

Lai, P. Y., Tamashiro, M., Fujil, J. K., Yates, J. R., and Su, N. Y. 1983. Sudan Red 7B, a dye marker for Coptotermes formosanus. Proceedings, Hawaiian Entomological Society 24: 277-282.

Levings, S. C. AND AdAMS, E. S. 1984. Intra- and interspecific territoriality in Nasutitermes (Isoptera: Termitidae) in a Panamanian mangrove forest. Journal of Animal Ecology 53: 705-714. 
Levings, S. C. and Traniello, J. F. A. 1981. Territoriality, nest dispersion, and community structure in ants. Psyche 88: 265-319.

NeL, J. J. C. 1968. Aggressive behaviour of the harvester termites Hodotermes mossambicus (Hagen) and Trinervitermes trinervoides (Sjöstedt). Insectes Sociaux 15: 145-156.

Prestwich, G. D. 1984. Defense mechanisms of termites. Annual Review of Entomology 29: 201-232.

Stuart, A. M. 1969. Social behavior and communication. In: Biology of Termites. Volume 1. Krishna, K. and Weesner, F. M. editors. pp. 193-232. Academic Press, New York and London.

Stuart, A. M. 1970. The role of chemicals in termite communication. In: Advances in Chemoreception Volume 1: Communication by Chemical Signals. Johnson, J. W. Jr., Moulton, D. G., and Turk, A. editors. pp. 79-106. Appleton-Century-Crofts, New York.

THORNE, B. L. 1982. Termite-termite interactions: workers as an agonistic caste. Psyche 89: 133-150.

Traniello, J. F. A. 1981. Enemy deterrence in the recruitment strategy of a termite: Soldier-organized foraging in Nasutitermes costalis. Proceedings, National Academy of Sciences, USA 78: 1976-1979. 

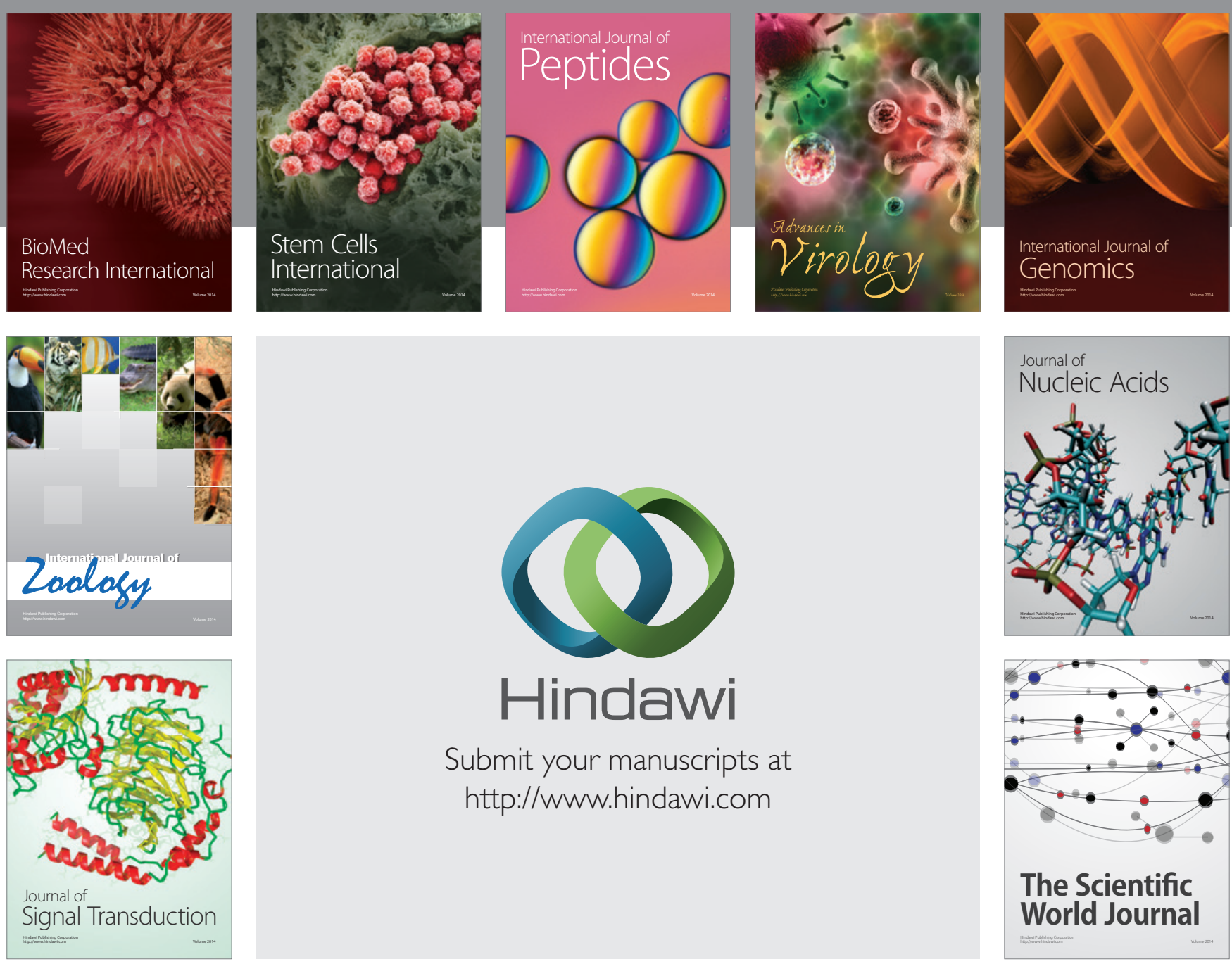

Submit your manuscripts at

http://www.hindawi.com
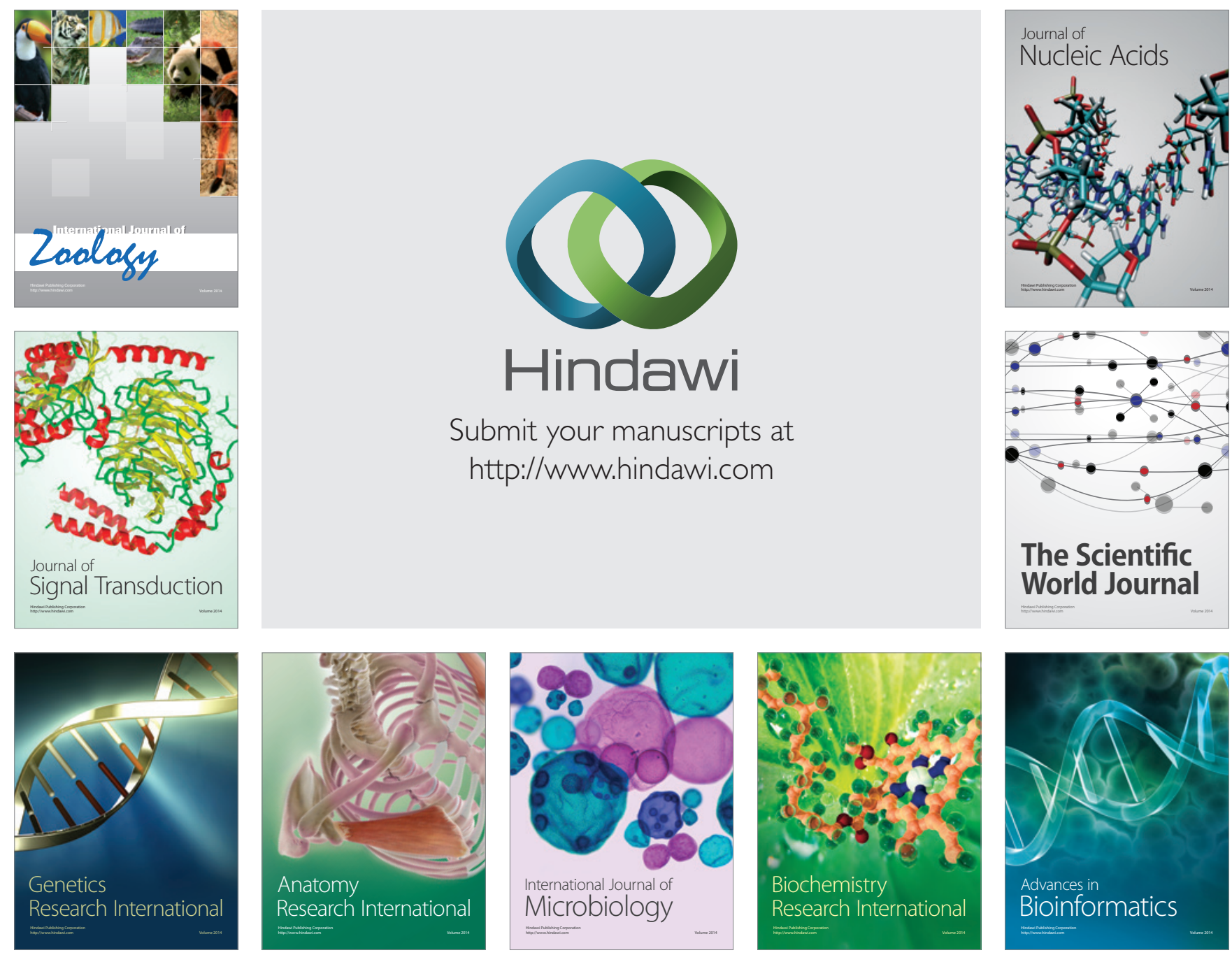

The Scientific World Journal
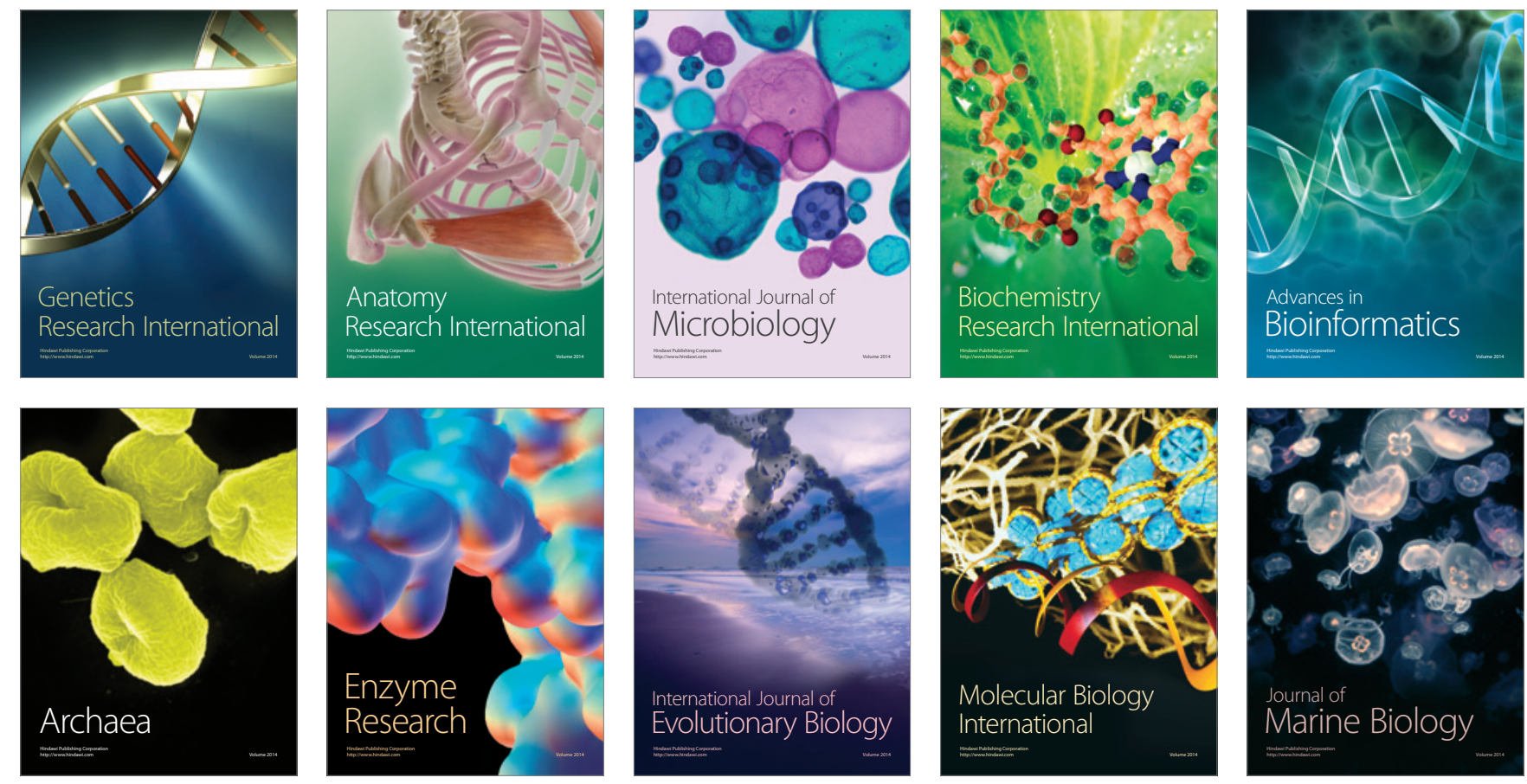